\title{
Towards the understanding of the molecular weight dependence of essential work of fracture in semi-crystalline polymers: A study on poly(E-caprolactone)
}

\author{
F. Tuba ${ }^{1,2^{*}}$, L. Oláh ${ }^{2}$, P. Nagy ${ }^{1}$ \\ ${ }^{1}$ Department of Polymer Engineering, Faculty of Mechanical Engineering, Budapest University of Technology and \\ Economics, Müegyetem rkp. 3., 1111 Budapest, Hungary \\ ${ }^{2}$ Audi Hungaria Motor Kft., Kardán utca 1., 9027 Győr, Hungary
}

Received 16 February 2014; accepted in revised form 23 June 2014

\begin{abstract}
The plane-stress ductile fracture of poly(E-caprolactone) (PCL) has been investigated as a function of molecular weight and related crystalline structure. Because of the interacting effects in semi-crystalline polymers a separate study of a given structural parameter is rather challenging. Nevertheless, this polymer seems to be a good model material to study the effect of molecular weight on the essential work of fracture, as the interactions between the separate parameters, at room temperature, are negligible. The molecular characteristics of PCL were determined by size exclusion chromatography. To confirm the entangled molecular structure of studied polymers rheological measurements were performed. The crystalline morphology has been characterized by differential scanning calorimetry and wide angle X-ray diffraction. Quasi-static tensile tests and essential work of fracture tests were performed to study the mechanical behavior. Based on the experimental observations an empirical model has been proposed to outline the molecular weight and crystallinity dependence of the essential work of fracture in this semi-crystalline polymer.
\end{abstract}

Keywords: biodegradable polymers, mechanical properties, poly(E-caprolactone) (PCL), essential work of fracture (EWF), molecular weight dependence

\section{Introduction}

Although often disregarded, fracture toughness is one of the most important aspects of material characteristics in engineering applications. Due to their stress concentrating effect, micro- and nanoscale cracks could induce catastrophic failure well below the load bearing ability of the material. To avoid this, effective flaw assessment methods have to be developed [1]. For the analysis of thick, rather brittle materials standardized test methods are available (ASTM E1820-11, ISO 12135). These are applicable under small-scale yielding conditions, i.e. up to a ligament yielding parameter - the ratio of the applied and the yield load - of 0.5. For ductile materials this parameter is usually above 0.8 , thus the linear elastic and adjusted methods generally underestimate the fracture resistance [1]. Additionally, thin-walled structures generally do not meet the thickness requirements of standardized methods, and the empirical equations describing geometry dependent plane-stress fracture resistance cannot treat the effects of ligament yielding. However, thin-walled elements are frequently used from simple packaging applications to lightweight-constructions of industrial areas like automotive, aerospace, shipbuilding, piping, etc.

Therefore, over the last decades several concepts have been developed to characterize the fracture of

\footnotetext{
${ }^{*}$ Corresponding author, e-mail: ferenc.tuba@audi.hu

(C) BME-PT
} 
ductile thin-walled geometries [1-3]. One of these is the essential work of fracture method (EWF), which became widespread as its test set-up is less complex and the restrictions of method are easier to fulfill compared to $J$-integral [4]. Originally the EWF method was developed for the analysis of ductile metals, and to describe elastic-plastic behavior from crack initiation through stable crack propagation under plane-stress conditions. The theory says that by testing geometrically similar specimens one can split the total fracture work $\left(W_{\mathrm{f}}\right)$ into a dissipative work of outer screening plastic zone $\left(W_{\mathrm{p}}\right)$, and into an essential one $\left(W_{\mathrm{e}}\right)$ that is required for the formation of the new crack surfaces in the inner fracture process zone. If the specimen is under quasi plane-stress conditions, the entire ligament $(L)$ yields before crack initiation, and the plastic zone is confined, then the plastic work is proportional to the plastic volume $\left(\beta \cdot B \cdot L^{2}\right)$, while the essential one is proportional to fracture area $(B \cdot L)$. Since both fracture works are assumed to be proportional to the initial cross section $(B \cdot L)$ and to the ligament length $(L)$; the total work of fracture can be partitioned into the specific essential $\left(w_{\mathrm{e}}\right)$ and non-essential $\left(w_{\mathrm{p}}\right)$ fracture terms (Equation (1)):

$\frac{W_{\mathrm{f}}}{B \cdot L}=w_{\mathrm{e}}+\beta \cdot w_{\mathrm{p}} \cdot L$

where $\beta[-]$ is a plastic zone shape dependent factor. It should be also noted that since in plane-stress the thickness has to be vanishingly small, the measured $w_{\mathrm{e}}$ and $w_{\mathrm{p}}$ are not true material constants, but functions of sheet thickness $(B)[3,5,6]$.

In polymers, because of their particular macromolecular and visco-elastic nature, further questions have arisen. One problem is that one can only talk of true plastic deformation when there are no frozen in stresses [7]. As the majority of 'plastic' deformation in polymers is reversible at elevated temperatures, the question has to be reformulated, and one has to focus on the magnitude of reversibility and minimize the frozen in stresses. To achieve this, a polymer is needed, which can be easily deformed, has a low elastic modulus and yield stress; i.e. the crystals have low plastic resistance. By these characteristics the void formation and the cavitation can be diminished or cavitation will not appear at all [8]. Additionally, below glass transition temperature $\left(T<T_{\mathrm{g}}\right)$ the constrained elastic deformations are favored, and problems like cold-drawing [9, 10], physical aging [11] or free-volume decrease [12] of amorphous phase, interfere with the obtained results. Other viscous effects, like strain-rate dependence (see e.g. $[9,10,13-15]$ ) or strain-induced crystallization [16] can also frustrate the final consequences. Despite all of these, for amorphous polymers and for thermoplastic elastomers several tendencies have been deduced and partly explained; for details see $[11,17]$.

The influencing parameters of EWF for semi-crystalline thermoplastics, however, remain still uncertain. The reason is that several factors influence the structure and amount of crystalline phase and these are strongly interrelated. These include [18]: molecular structure, molecular weight and its distribution; crystalline phase and structure; the amount, order and orientation of crystalline fraction; spherulite size; lamellae thickness; chain branching; number and density of tie molecules; etc.

By starting with molecular structure and related glass transition temperature, the investigated materials can be divided into two groups. In studies performed (i) below glass transition temperature (see e.g. [19-22]) the previously mentioned entropyelastic deformations dominate the failure, thus similar observations can be made than in case of amorphous thermoplastics and elastomers [17]. The other group of investigations includes materials, which were tested (ii) above their glass transition temperature, like polyethylenes [23, 24], polypropylenes $[19,20,25-28]$, polyesters [21], poly(vinylidenefluoride) [29], etc. In these polymers the cold-drawing in the amorphous glass is less significant and the effect of crystallinity can be emphasized.

The molecular weight dependence has been studied by Sheng et al. [27] on ethylene-propylene block copolymers with crystallinity change of less than $5 \%$. They found that we increases linearly with the number average molecular weight $\left(M_{\mathrm{n}}\right) \cdot \beta \cdot w_{\mathrm{p}}$ was chiefly influenced by the amount of high molecular weight component; the increase of long-chain length fraction led to reduced ductility.

Mouzakis et al. [28] studied the effect of stereoregularity on the crystallinity and fracture properties of elastomeric polypropylene. It was found that we increases, but $\beta \cdot w_{\mathrm{p}}$ decreases with decreasing crystallinity. Nevertheless, it should be noted that the molecular characteristics of samples were not presented. 
Barry and Delatycki [30] showed in high density polyethylene that the thicker crystalline lamellae and the more ordered crystalline structure results in increased resistance to crack initiation. Conversely, the crack growth resistance decreased with increasing concentration of side chains.

Gupta et al. [24] studied the effect of side chain length on the deformation mechanisms of linear low density polyethylenes of similar molecular characteristics and crystallinity. They found that the longer the side chain the higher the essential work of fracture, which was explained by an anchoring effect of longer chain segments.

Channel and Clutton [31] studied the effect of molecular weight and chain branching in a series of polyethylenes under impact conditions and found that fracture toughness $\left(G_{\mathrm{c}}\right)$ increases linearly with increasing molecular weight. It was stated that the increase in molecular weight increases the number of tie molecules, that is accompanied by increased toughness [18].

Based on this literature overview it can be deduced that the raise in tie molecule density and lamellae thickness seem to increase the resistance to crack initiation and the value of $w_{\mathrm{e}}$. The effect of crystallinity on $w_{\mathrm{e}}$ and the influencing factors of plastic work of fracture $\left(\beta \cdot w_{\mathrm{p}}\right)$ are, however, more obscure. This study is addressed to describe the fracture behavior of poly( $\varepsilon$-caprolactone) (PCL) as a function of molecular weight and crystalline morphology. As PCL at room temperature is well above its glass transition temperature $\left(T_{\mathrm{g}} \approx-60^{\circ} \mathrm{C}[32]\right)$, its amorphous phase has high compliance, which minimizes the magnitude of frozen in stresses, entropyelastic deformation. Additionally, the reported problems like the orientation, physical aging $[11,33]$ or free-volume decrease [12] of amorphous glass phase do not interfere with the obtained results. The deformation in this state and at low deformation rates is assumed to be composed from the viscoplastic deformation of amorphous regions and the elasto-plastic deformation of crystalline spherulites.

To initiate the unloosening of crystallites one has to reach a critical stress, where the irreversible deformation starts. Men et al. [34] has shown that this critical stress is in connection with the intrinsic stability of crystals, which is related to their theoretical equilibrium melting temperature. The low melting temperature of PCL leads to the deformation of crystallites at lower stresses, compared to other semi-crys- talline polyolefins, polyesters and this also helps to minimize the cold-drawing and orientation of amorphous network.

The micromechanical deformation of spherulitic crystalline phase, however, also has various subregions [35]. The crystalline lamellae first breaks into smaller blocks and those that are diagonally to the loading direction start to rotate and slip. As the deformability of crystalline lamellae is one order of magnitude smaller in the folding direction than perpendicular to it [7], the tearing of tie molecules is the dominant process in the equatorial regions, while in the polar directions the less stable structure promotes the unloosing of lamellar build-up.

The phase transition of crystalline parts also influences the fracture properties as it was reported by Ferrer-Balas et al. [25] for polypropylene. PCL, in contrast, has a stable orthorhombic ( $\left.\mathrm{P} 2_{1} 2_{1} 2_{1}\right)$ crystalline structure with non-planar chain packing conformation in the crystalline lamellae [36, 37], thus these phase transitions have no effect on the fracture behavior either.

Summarily, PCL owing to its low melting and glass transition temperature, low yield stress, linear molecular and stable orthorhombic crystalline structure is in favorable state at room temperature to test the effect of molecular weight and crystalline phase on the essential work of fracture parameters of semicrystalline polymers.

\section{Experimental}

\subsection{Applied materials}

For the studies four different poly( $\varepsilon$-caprolactone) (Perstorp Caprolactones, Perstorp UK Ltd, UK) samples were used. The molecular characteristics number average molecular weight $\left(M_{\mathrm{n}}\right)$ and polydispersity $\left(M_{\mathrm{w}} / M_{\mathrm{n}}\right)$ - were determined after compression moulding by size exclusion chromatography according to ISO 16014 in tetrahydrofuran at $35^{\circ} \mathrm{C}$ with a Waters chromatograph (Waters Corp., USA). The obtained results are listed in Table 1. The polydispersity values are comparable, thus the obtained results based on a specific molecular weight are comparable.

Table 1. Molecular characteristics of the examined PCLs

\begin{tabular}{|c|c|c|c|c|}
\hline Name & Capa 6250 & Capa 6400 & Capa 6500 & Capa 6800 \\
\hline$M_{\mathrm{n}}[\mathrm{kg} / \mathrm{mol}]$ & 31.1 & 39.8 & 61.8 & 85.1 \\
\hline$M_{\mathrm{w}} / M_{\mathrm{n}}[-]$ & 1.6 & 1.6 & 1.7 & 1.9 \\
\hline
\end{tabular}

$M_{\mathrm{n}}$ - number average molecular weight

$M_{\mathrm{w}}$ - weight average molecular weight 


\subsection{Sample processing}

Tensile test specimens (ISO 527 type 1BA) and sheets with a thickness $(B)$ of $0.5 \mathrm{~mm}$ were hot pressed using a COLLIN P-200E-type (Dr. Collin $\mathrm{GmbH}$, Germany) compression molding machine at pressure of $5 \mathrm{MPa}$ and temperature of $100^{\circ} \mathrm{C}$. The samples were pre-heated for 5 minutes without load, followed by a 5 minute-hold under load and by water-cooling to room temperature with a rate of $10^{\circ} \mathrm{C} / \mathrm{min}$.

The fracture tests were performed on double edge notched tensile (DENT, Figure 1) specimens. Samples with a width $(W)$ of $40 \mathrm{~mm}$ and length $(H)$ of $80 \mathrm{~mm}$ (clamped length $40 \mathrm{~mm}$ ) were machined from the sheets $(B=0.5 \mathrm{~mm})$. The ligament lengths $(L)$ varied between 4 and $13 \mathrm{~mm}$ and were prepared by aligned razor blades. The ligament lengths were measured by an optical microscope (Olympus BX $51 \mathrm{M}$, Olympus Corp., Japan) prior testing.

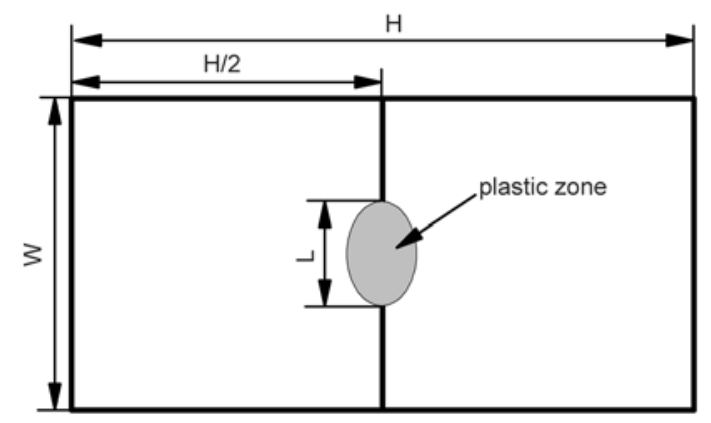

Figure 1. Geometry of DENT specimens

\subsection{Analytical techniques}

The rheological properties of PCL melts were determined using a plate-plate rheometer (AR2000; TA Instruments, USA) at $100^{\circ} \mathrm{C}$ in the shear-rate range of 0.01 and $51 / \mathrm{s}$. The zero-shear viscosity $\left(\eta_{0}\right)$ was determined from the shear-rate versus dynamic-viscosity curves by assuming Newtonian behavior.

Wide-angle X-ray diffraction (WAXD) measurements were performed on compression molded sheets and on the deformed ligament region of DENT specimens. The patterns were recorded on X'pert PRO MPD (PANalytical B.V., The Netherlands) X-ray diffractometer equipped with an $\mathrm{X}^{\prime}$ Celerator detector and using $\mathrm{Cu} \mathrm{K} \mathrm{K}_{\alpha}$ radiation $(\lambda=0.1542 \mathrm{~nm})$.

Differential scanning calorimetry (DSC) was carried out on the samples by a Mettler-Toledo DSC1 (Mettler-Toledo GmbH, Switzerland). The purge gas was nitrogen $(30 \mathrm{~mL} / \mathrm{min})$, while liquid nitrogen was used for the cooling. The measurements were carried out between -30 and $100^{\circ} \mathrm{C}$ with a heating and cooling rate of $10^{\circ} \mathrm{C} / \mathrm{min}$. The results were evaluated according to ISO 11357-3 standard. The crystallinity of the samples was calculated by taking the enthalpy of fusion of the $100 \%$ crystalline polymer as $\Delta H_{0}=142.5 \mathrm{~J} / \mathrm{g}$ [38].

The tensile and fracture tests were performed at ambient conditions $\left(24 \pm 1^{\circ} \mathrm{C}, \mathrm{RH}=40 \pm 5 \%\right)$ on a Zwick Z020 (Zwick GmbH, Germany) universal testing machine. The crosshead speed was set to $10 \mathrm{~mm} / \mathrm{min}$, the displacement values were calculated from crosshead travel, while the force values were recorded by a $20 \mathrm{kN}$ loading cell. For the determination of tensile properties five dumb-bell specimens were tested for each material. For the linear regression of EWF data at least 20 specimens were used.

\subsection{EWF method and the data limitation of concept}

Based on Equation (1) the linear regression of specific work of fracture $\left(w_{\mathrm{f}}=W_{\mathrm{f}} /(L \cdot B)\right)$ versus ligament length $(L)$ plots yields in the specific essential work of fracture $\left(w_{\mathrm{e}}\right)$ - ordinate intercept - and in the plastic work of fracture $\left(\beta w_{\mathrm{p}}\right)$ - the slope of the fitted line. However, Equation (1) is only valid if the prerequisites of EWF method are met. Under mode I load - tests on double edge notched tensile specimens (DENT; Figure 1.) - these conditions are:

- full ligament yielding prior to crack initiation,

- quasi plane-stress conditions during crack propagation,

- confined plastic zone,

- geometrical similarity of specimens.

There are several empirical and theoretical criteria that help to ensure the above mentioned conditions (see e.g. $[4,11,39,40]$ ), but the adequacy of these criteria still remains a relevant issue [41-43]. In this paper - based on previous studies [41-43] - the following prerequisites have been used:

- necking of the fracture process zone

- self-similarity of load-displacement curves (see Figure 2),

- a lower ligament limit, which was determined as outlined in our previous paper [43] to ensure quasi plane-stress conditions and steady-state crack propagation,

- a confined plastic zone was ensured by the condition $L<\operatorname{Min}\left(W / 3, x_{\mathrm{p}}\right)[11]$, where $x_{\mathrm{p}}$ is the esti- 

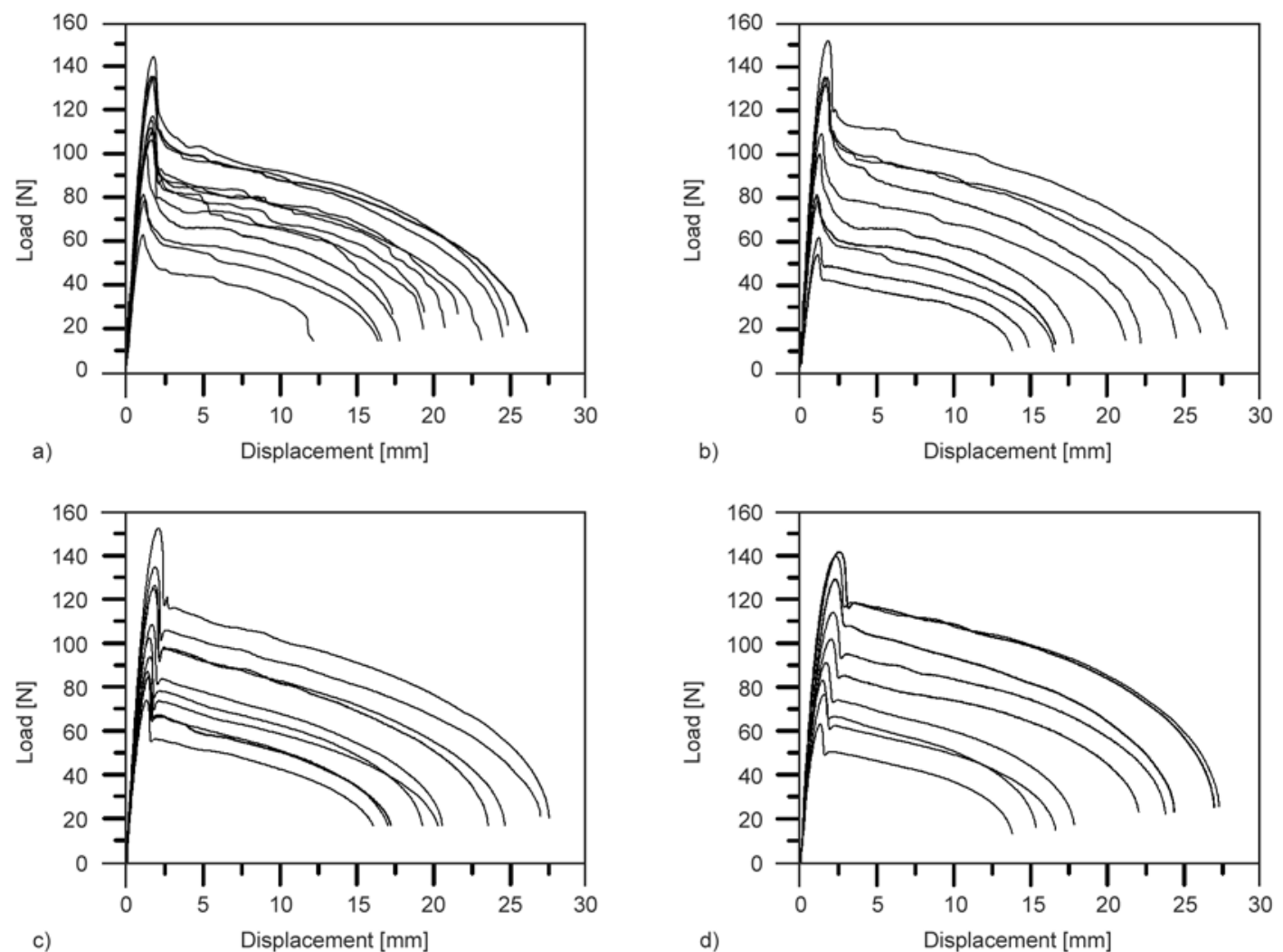

Figure 2. Characteristic load-displacement curves of the studied DENT samples: (a) Capa 6250, (b) Capa 6400, (c) Capa 6500 and (d) Capa 6800

mated size of the plastic zone based on Cotterell's study [4], and

- ligament yielding was verified by the method described in [42].

\section{Results and discussion}

\subsection{Morphology of amorphous and crystalline phase}

The zero-shear viscosity $\left(\eta_{0}\right)$ of polymer melts is proportional to the molecular weight $\left(M_{\mathrm{n}}\right)$, i.e. to the number of backbone atoms [44]. This dependence can be described by Equation (2):

$\eta_{0} \propto M_{\mathrm{n}} \alpha$

where $\alpha$ is an exponential factor having a value of $1<\alpha<2.5$ for polymers below a critical molecular weight $\left(M_{\mathrm{c}}\right)$ [45], and $\alpha=3.4$ for materials above their $M_{\mathrm{c}}$.

This critical molecular weight has been interpreted as the molecular weight required for the formation of entanglements [44]. Based on Equation (2) the $\log \eta_{0}$ versus $\log M_{\mathrm{n}}$ plot shown in Figure 3 yields in $\alpha=3.41\left(R^{2}=0.98\right)$, which confirms the presence

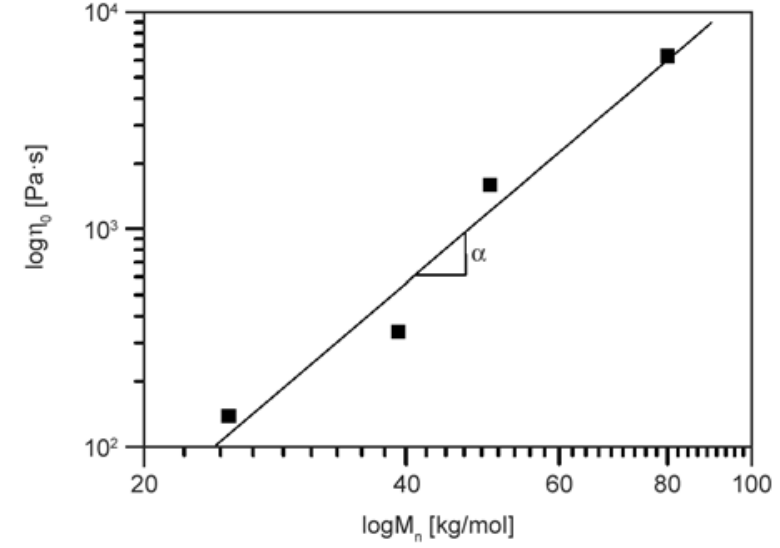

Figure 3. Zero-shear-viscosity as a function of number average molecular weight for PCL samples

of entangled amorphous network in the studied materials.

The WAXD plots (Figure 4) indicate that the PCLs of different molecular weight have the same crystalline structure prior to mechanical testing so the results are comparable and are not influenced by artifacts resulting from different crystalline arrangements.

As it was shown by Skoglund and Fransson [46] bulk PCL crystallizes in spherulitic morphology 


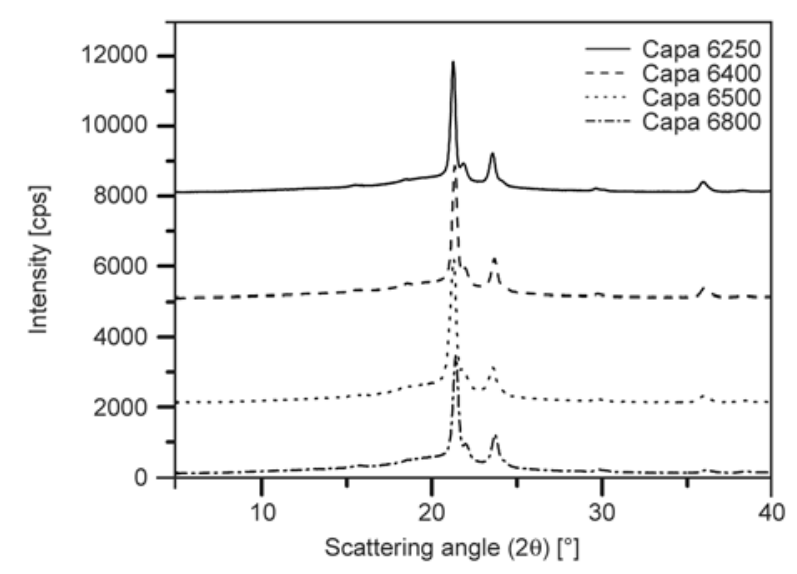

Figure 4. WAXD plots of PCLs with different molecular characteristics

independent of the crystallization procedure. They also reported that the crystallization is nucleation controlled and the kinetics is slower for higher molecular weight samples. The slower kinetics can be explained with the retarded segmental mobility of the longer chains. As a result of this the crystallinity decreases with increasing $M_{\mathrm{n}}$. The crystallization peak temperature was $29 \pm 1^{\circ} \mathrm{C}$ for the materials investigated, thus the degree of supercooling can be taken as constant. In Figure 5 it is observable that the obtained crystallinity values are in good agreement with the results of Skoglund and Franson [46] and Pitt et al. [47]. At high molecular weights the crystallinity is about $40 \%$, rising to around $75 \%$ as the $M_{\mathrm{n}}$ decreases to $\sim 10 \mathrm{~kg} / \mathrm{mol}$.

According to the Thomson-Gibbs equation [48] the melting temperature $\left(T_{\mathrm{m}}\right)$ of a crystallite is related to its lamellar thickness $(D)$ (Equation (3)):

$$
T_{\mathrm{m}} \propto T_{\mathrm{m}}^{0}\left(1-\frac{1}{D}\right)
$$

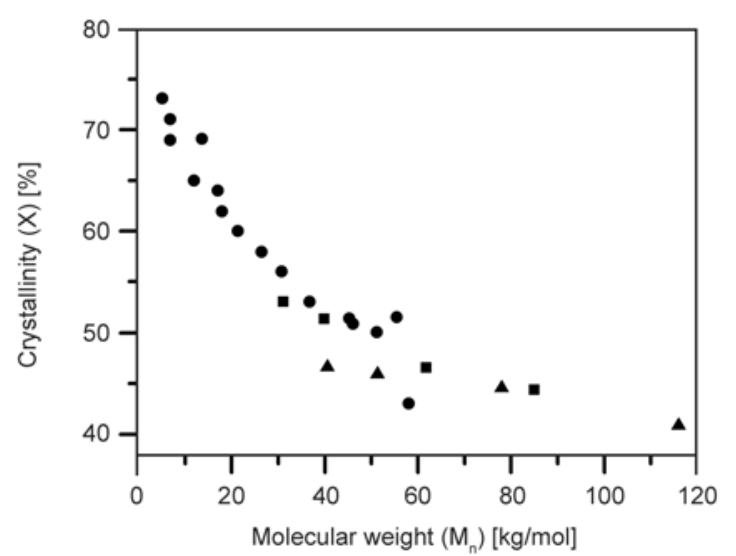

Figure 5. Relationship between the crystallinity and the molecular weight of PCL (•-Pitt et al. [47], $\Delta$ - Skoglund and Franson [46] - - this study)

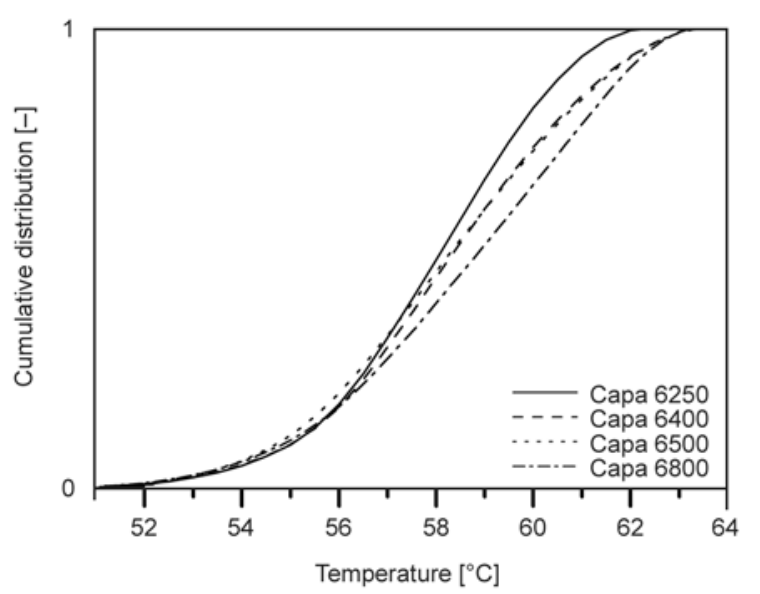

Figure 6. Cumulative distribution of crystalline lamellae with different melting temperatures

As $T_{\mathrm{m}}^{0}$ is practically independent of molecular weight for the examined materials - it was shown by Chen et al. [49] that above $M_{\mathrm{n}} \approx 20 \mathrm{~kg} / \mathrm{mol}$ the theoretical equilibrium melting point $\left(T_{\mathrm{m}}^{0}\right)$ of PCL can be taken as constant-, the lamellar thickness distribution can be estimated from the DSC melting endotherms as shown in Figure 6. The above mentioned difference in folding kinetics did not result in a considerable deviation of melting temperatures, i.e. lamellae thickness.

As it is shown in Figure 7 neither the onset $\left(T_{\text {on }}\right)$ and end temperatures ( $\left.T_{\text {end }}\right)$ nor the peak temperatures $\left(T_{\mathrm{mp}}\right)$ differ significantly $(p<0.05)$. Only the amount of crystalline phase $(X)$ decreases with increasing molecular weight, which is a result of retarded chain mobility of longer molecules.

To summarize, PCL seems to be a rational model material to investigate the effect of molecular weight induced crystallinity changes on the fracture properties. The change in molecular characteristics influences the amount of crystalline fraction and the

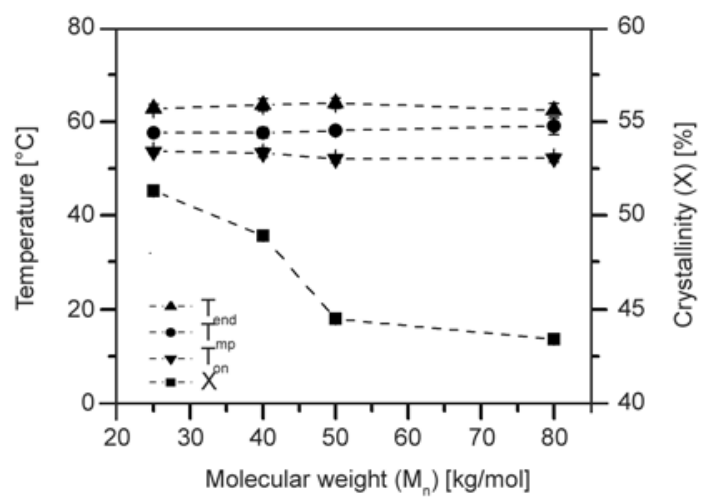

Figure 7. Melting characteristics of PCL as a function of molecular weight 
density of tie molecules, entanglements only. The crystalline structure, order and lamellae thickness appear to be independent of examined molecular weight range, while there is no preferred orientation in the crystalline structure due to the sample processing method.

Nevertheless, the reduced segmental mobility of longer molecules led to decreasing crystallinity.The increase in molecular weight also increases the entanglement density of amorphous phase. Additionally the longer molecules could cross several crystalline lamellae, thus the tie molecule density of higher molecular weight samples also increases. As a consequence, the interconnectivity of amorphous and crystalline 'networks' grows with increasing molecular weight.

\subsection{Mechanical properties}

In PCL the low glass transition temperature and the less stable crystalline structure result in highly ductile deformation under ambient conditions. Owing to the relatively slow deformation rate, the tensile specimens did not fail up to an elongation of $200 \%$. As the specimen end regions yielded at these high deformations, the elongation at break and engineering break stress values could not be determined (see ISO 527).

As it is shown in Table 2, the Young's modulus $(E)$ and yield stress $\left(\sigma_{\mathrm{Y}}\right)$ values decrease, while the elongation at yield $\left(\varepsilon_{\mathrm{Y}}\right)$ rises with increasing molecular weight. The descending modulus, yield stress as well as the growing elongation at yield values are indicative of a less rigid, more compliant structure. This can be explained by the influence of crystallinity, i.e. by the amount of stiff crystalline phase. As the studied PCL is well above its glass transition temperature the amorphous phase has mainly stress transferring role and the load is chiefly carried by the interconnected crystalline network. However, to support this hypothesis one has to eliminate the influence of the amount of crystalline phase.

By normalizing the measured tensile properties with crystallinity (Figure 8) it is observable that above $40 \mathrm{~kg} / \mathrm{mol}$ the normalized tensile modulus

Table 2. Tensile characteristics of the examined materials

\begin{tabular}{|l|c|c|c|c|}
\hline \multicolumn{1}{|c|}{ Name } & Capa 6250 & Capa 6400 & Capa 6500 & Capa 6800 \\
\hline$E[\mathrm{MPa}]$ & $429 \pm 41$ & $348 \pm 19$ & $310 \pm 41$ & $295 \pm 4$ \\
\hline$\sigma_{\mathrm{Y}}[\mathrm{MPa}]$ & $16.7 \pm 0.7$ & $14.5 \pm 0.1$ & $13.2 \pm 0.4$ & $12.8 \pm 0.2$ \\
\hline$\varepsilon_{\mathrm{Y}}[\%]$ & $9.6 \pm 0.7$ & $11.9 \pm 0.3$ & $12.2 \pm 1.2$ & $14.7 \pm 0.3$ \\
\hline
\end{tabular}

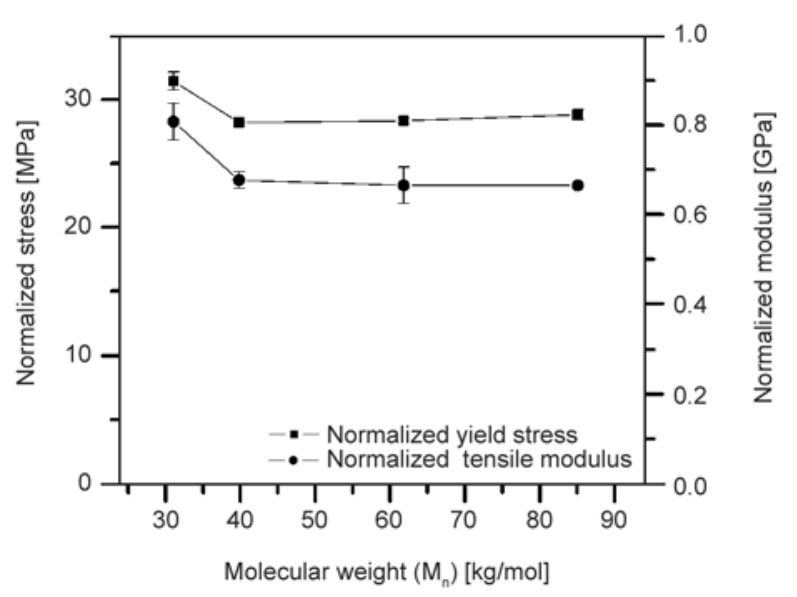

Figure 8. Normalized tensile properties as a function of number average molecular weight

$(E / X)$ and yield stress $\left(\sigma_{\mathrm{Y}} / X\right)$ values are independent of molecular weight $(p<0.05)$. This observation suggests that during tensile tests the molecule length, the number of entanglements and tie molecules in amorphous regions do not influence the deformability of crystalline phase.

The only exception is the low molecular weight sample (Capa 6250). It should be noted, however, that this polymer can be annealed at room temperature. This process is rather fast, and several hours of 'annealing' - delay between the measurements of crystallinity and mechanical properties - may lead to significant changes in the crystalline structure, crystallinity and mechanical properties [50]. Therefore, this point is treated as an artefact.

After yielding, the unloosing of crystalline structure led to decreasing crystallinity as it is shown on the WAXD plots of Figure 9. The broadening of WAXD peaks also suggests the deformation of crystalline structure [51].

From the full-width-at-half-maximum (FWHM) values of reflections of (110) plane [37] one can derive information about the mean lateral dimension of the crystallites. As the Scherrer-equation says the mean lateral dimension of the crystallites of a polycrystalline sample is inversely proportional to the full-width-at-half-maximum of a diffraction peak (at a given $\theta$ scattering angle and $\lambda$ wavelength). In Capa 6250 only a slight increase of FWHM was observed - negligible rearrangement of crystallites during the deformation -, however, in higher molecular weight samples the change was more significant (Figure 9b). The mean lateral dimension values were only the third of their initial value, which suggests more intense deformations, crystalline- 

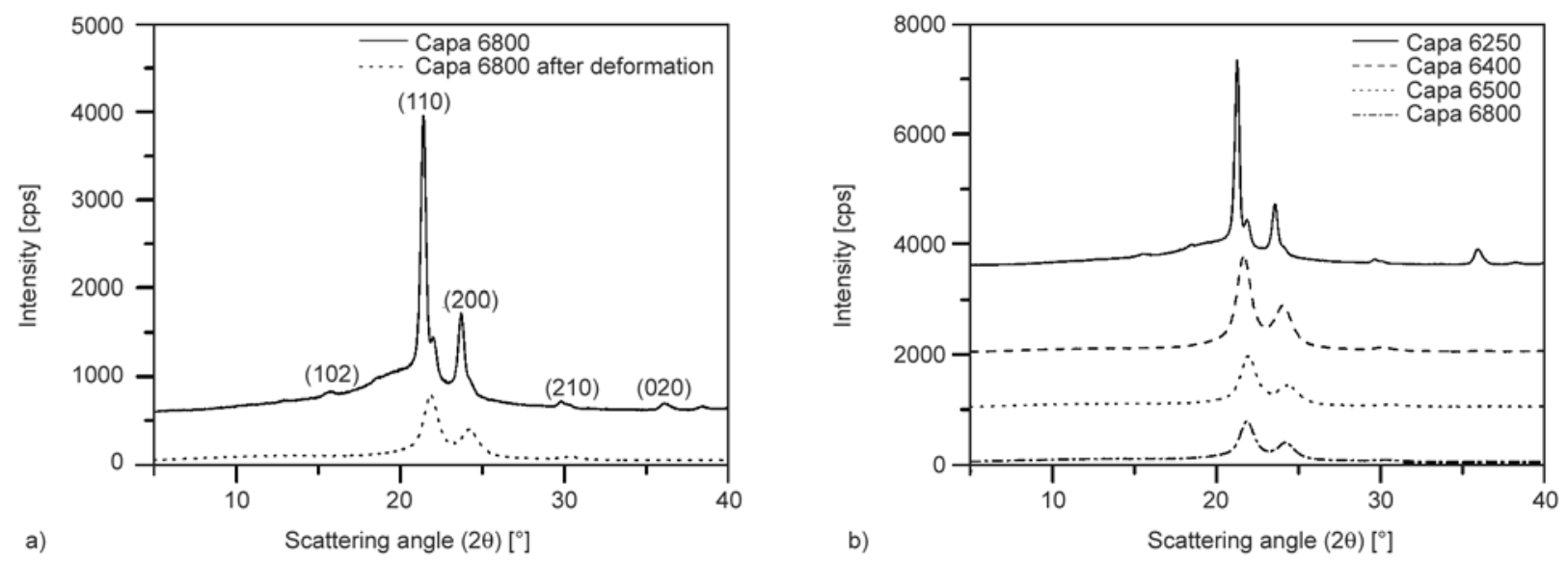

Figure 9. WAXD plots of (a) undeformed and deformed Capa 6800 and (b) deformed PCLs as a function of molecular weight (DENT specimens)

size-refinement and the unloosing of crystalline domains.

Table 3 summarizes the obtained work of fracture parameters for different molecular weight PCLs. All samples fulfilled the requirements outlined in Section 2.4. As a result of enhanced tie molecule and entanglement density (Figure 3 ) the essential work of fracture terms increase with molecular weight. Additionally, the longer molecules are able to form more secondary bonds, thus the initiation of unloosing and tearing of polymer chain from crystalline lamellae also consumes more energy and raises the essential work of fracture.

After plotting the essential work of fracture values as a function of molecular weight the data lie on a line with positive intercept $\left(R^{2}=0.9670\right)$, as it was observed by Sheng et al. [27] during EWF tests on polyethylene-polypropylene block copolymers, or by Channel and Clutton [31] during impact fracture tests. The goodness of fit can be further improved after incorporating the effect of crystallinity in a same way as done in tensile tests. The regression coefficient of normalized essential work of fracture versus molecular weight line increases to a remarkable $R^{2}=0.9954$ (Figure 10). This correlation can be described by Equation (4):

Table 3. Effect of molecular weight on fracture parameters and the parameters of linear fit

\begin{tabular}{|c|c|c|c|c|}
\hline Name & $\begin{array}{c}\mathbf{w}_{\mathbf{e}} \\
{\left[\mathbf{k J} / \mathbf{m}^{2}\right]}\end{array}$ & $\begin{array}{c}\boldsymbol{\beta} \cdot \mathbf{w}_{\mathbf{p}} \\
{\left[\mathbf{M J} / \mathbf{m}^{3}\right]}\end{array}$ & $\begin{array}{c}\mathbf{R}^{2} \\
{[-]}\end{array}$ & $\begin{array}{c}\mathbf{S D} \\
{\left[\mathbf{k J} / \mathbf{m}^{2}\right]}\end{array}$ \\
\hline Capa 6250 & $45.7 \pm 3.2$ & $19.9 \pm 0.4$ & 0.9901 & 5.2 \\
\hline Capa 6400 & $48.3 \pm 4.4$ & $27.6 \pm 0.5$ & 0.9951 & 6.3 \\
\hline Capa 6500 & $50.5 \pm 5.1$ & $21.9 \pm 0.6$ & 0.9891 & 6.7 \\
\hline Capa 6800 & $55.9 \pm 2.2$ & $16.5 \pm 0.2$ & 0.9955 & 3.4 \\
\hline
\end{tabular}

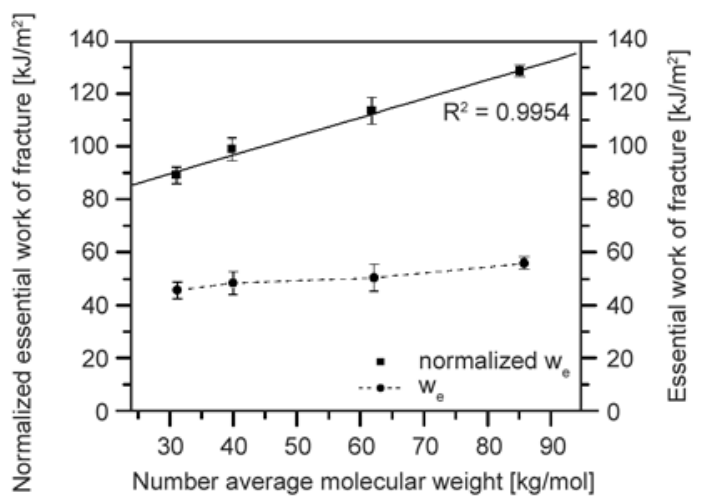

Figure 10. Essential work of fracture versus number average molecular weight plots of PCL

$w_{\mathrm{e}}=\left(w_{\mathrm{e} 0}+a \cdot M_{\mathrm{n}}\right) \cdot X$

where $w_{\mathrm{e} 0}\left[\mathrm{~kJ} / \mathrm{m}^{2}\right]$ is the intrinsic essential work of fracture, which could be a material dependent parameter, $a\left[\mathrm{~kJ} \cdot \mathrm{mol} / \mathrm{kg} \cdot \mathrm{m}^{2}\right]$ is a variable depending on the entanglement and tie molecule density of a specific material, $M_{\mathrm{n}}[\mathrm{kg} / \mathrm{mol}]$ is the number average molecular weight and $X[-]$ is the crystallinity. For PCL the constant values are $a=0.713 \mathrm{~kJ} \cdot \mathrm{mol} / \mathrm{kg} \cdot \mathrm{m}^{2}$ and $w_{\mathrm{e} 0}=68.7 \mathrm{~kJ} / \mathrm{m}^{2}$.

The dissipative component originates mainly from the various slips and rotations of crystalline blocks and from the unloosing of chain segments in the outer dissipative volume of the fracture $\left(\beta \cdot B \cdot L^{2}\right)$. The related work of fracture parameter $\left(\beta \cdot w_{\mathrm{p}}\right)$ has a maximum between $M_{\mathrm{n}}=40$ and $60 \mathrm{~kg} / \mathrm{mol}$. This observation could be explained by the opposing effects of crystalline build up, crystallinity and amorphous phase entanglement density, respectively. At low molecular weights, the less entangled amorphous network, the shorter tie molecules facilitate the rotation and slip of crystalline blocks, while the 
higher crystallinity - stiffer network - hinder the energy dissipative deformations (small $\beta \cdot w_{\mathrm{p}}$ values). As a result, the unloosing of crystalline network was nearly absent in the Capa 6250 sample (see Figure $9 \mathrm{~b}$ ). With growing molecular weight the crystallinity drops, the compliance of crystalline phase increases, it can be deformed easier and $\beta \cdot w_{\mathrm{p}}$ also increases (Capa 6400 and 6500). This observation is in contrast with the findings of Mouzakis et al. [28]; however the molecular charateristics of the samples studied are not known.

On the other hand, at high molecular weights the crystallinity remains nearly constant (for $M_{\mathrm{n}}$ higher than $\sim 60 \mathrm{~kg} / \mathrm{mol}$, see Figure 5), but the rising entanglement density of amorphous network acts as a barrier for the energy dissipative mechanisms, leading to the decrease of $\beta \cdot w_{\mathrm{p}}$ (Capa 6800), similarly as found by Sheng et al. [27].

\section{Conclusions}

The molecular weight and crystallinity dependence of essential work of fracture of semi-crystalline poly( $\varepsilon$-caprolactone) (PCL) have been characterized in this study. Based on wide angle X-ray diffraction and differential scanning calorimetric measurements, the crystalline structure and lamellae thickness distribution were found to be independent of molecular weight, only the crystallinity decreased as a result of slower kinetics of longer molecules.

The tensile mechanical properties were mainly governed by the amount of load-carrying crystalline phase; the amorphous regions acted chiefly as stress transferring zones. The Young's modulus and yield stress of samples decreased with increasing molecular weight and crystallinity, but after normalizing with crystallinity they had a constant value.

The fracture behavior was studied by the essential work of fracture method, which is suitable for the description of the fracture of thin ductile materials under quasi plane stress conditions. The plastic deformation and unloosening of crystalline structure has been confirmed by wide angle X-ray diffraction measurements. The essential work of fracture work required for the generation of new crack-surfaces - increased with increasing molecular weight as a result of increasing tie molecule length and density. After normalizing with crystallinity linear correlation was found between the normalized essential work of fracture and number average molecular weight.
The decrease of tie molecule density and the raise of either the crystallinity or the entanglement density of amorphous network acted as a barrier in relation to the plastic fracture work - dissipated energy in the plastic zone. As a result the non-essential work of fracture had a maximum between $M_{\mathrm{n}}=40$ and $60 \mathrm{~kg} / \mathrm{mol}$, where these counteractive effects were in balance.

\section{Acknowledgements}

The authors are indebted to János Madarász (Department of Inorganic and Analytical Chemistry, Budapest University of Technology and Economics) for his help in the X-ray diffraction measurements. This work is connected to the scientific program of the 1Development of quality-oriented and harmonized $\mathrm{R}+\mathrm{D}+\mathrm{I}$ strategy and functional model at BME1 (Project ID: TÁMOP-4.2.1/B-09/1/KMR-2010-0002) and the 'Talent care and cultivation in the scientific workshops of BME' (Project ID: TÁMOP - 4.2.2.B-10/1--2010-0009) projects.

\section{References}

[1] Zerbst U., Heinimann M., Donne C. D., Steglich D.: Fracture and damage mechanics modelling of thinwalled structures - An overview. Engineering Fracture Mechanics, 76, 5-43 (2009).

DOI: $10.1016 /$ j.engfracmech.2007.10.005

[2] Schwalbe K-H., Newman Jr J. C., Shannon Jr J. L.: Fracture mechanics testing on specimens with low constraint-standardisation activities within ISO and ASTM. Engineering Fracture Mechanics, 72, 557-576 (2005).

DOI: 10.1016/j.engfracmech.2004.04.006

[3] Cotterell B., Reddel J. K.: The essential work of plane stress ductile fracture. International Journal of Fracture, 13, 267-277 (1977).

DOI: $10.1007 / \mathrm{BF} 00040143$

[4] Cotterell B., Pardoen T., Atkins A. G.: Measuring toughness and the cohesive stress-displacement relationship by the essential work of fracture concept. Engineering Fracture Mechanics, 72, 827-848 (2005). DOI: $10.1016 /$ j.engfracmech.2004.10.002

[5] Hill R.: On discontinuous plastic states, with special reference to localized necking in thin sheets. Journal of the Mechanics and Physics of Solids, 1, 19-30 (1952). DOI: 10.1016/0022-5096(52)90003-3

[6] Pardoen T., Marchal Y., Delannay F.: Thickness dependence of cracking resistance in thin aluminium plates. Journal of the Mechanics and Physics of Solids, 47, 2093-2123 (1999).

DOI: 10.1016/S0022-5096(99)00011-3

[7] Kausch H. H.: Polymer fracture. Springer Verlag, Heidelberg (1978). 
[8] Pawlak A., Galeski A.: Plastic deformation of crystalline polymers: The role of cavitation and crystal plasticity. Macromolecules, 38, 9688-9697 (2005).

DOI: $10.1021 / \mathrm{ma} 0508420$

[9] Karger-Kocsis J., Czigány T., Moskala E. J.: Deformation rate dependence of the essential and non-essential work of fracture parameters in an amorphous copolyester. Polymer, 39, 3939-3944 (1998).

DOI: 10.1016/S0032-3861(98)00029-9

[10] Karger-Kocsis J., Moskala E. J.: Molecular dependence of the essential and non-essential work of fracture of amorphous films of poly(ethylene-2,6-naphthalate) (PEN). Polymer, 41, 6301-6310 (2000).

DOI: 10.1016/S0032-3861(99)00866-6

[11] Bárány T., Czigány T., Karger-Kocsis J.: Application of the essential work of fracture (EWF) concept for polymers, related blends and composites: A review. Progress in Polymer Science, 35, 1257-1287 (2010).

DOI: 10.1016/j.progpolymsci.2010.07.001

[12] Gámez-Pérez J., Velazquez-Infante J. C., FrancoUrquiza E., Pages P., Carrasco F., Santana O. O., Maspoch M. L.: Fracture behavior of quenched poly(lactic acid). Express Polymer Letters, 5, 82-91 (2011). DOI: $10.3144 /$ expresspolymlett.2011.9

[13] Maspoch M. L., Gámez-Pérez J., Karger-Kocsis J.: Effects of thickness, deformation rate and energy partitioning on the work of fracture parameters of uPVC films. Polymer Bulletin, 50, 279-286 (2003).

DOI: 10.1007/s00289-003-0169-5

[14] Ching E. C. Y., Li R. K. Y., Mai Y-W.: Effects of gauge length and strain rate on fracture toughness of polyethylene terephthalate glycol (PETG) film using the essential work of fracture analysis. Polymer Engineering and Science, 40, 310-319 (2000).

DOI: $10.1002 /$ pen.11164

[15] Ching E. C. Y., Poon W. K. Y., Li R. K. Y., Mai Y-W.: Effect of strain rate on the fracture toughness of some ductile polymers using the essential work of fracture (EWF) approach. Polymer Engineering and Science, 40, 2558-2568 (2000).

DOI: $10.1002 /$ pen.11386

[16] Chen H., Karger-Kocsis J., Wu J.: Effects of molecular structure on the essential work of fracture of amorphous copolyesters at various deformation rates. Polymer, 45, 6375-6382 (2004).

DOI: $10.1016 /$ j.polymer.2004.07.007

[17] Chen H., Wu J.: Understanding the underlying physics of the essential work of fracture on the molecular level. Macromolecules, 40, 4322-4326 (2007).

DOI: $10.1021 / \mathrm{ma} 062567 \mathrm{r}$

[18] Karger-Kocsis J.: Dependence of the fracture and fatigue performance of polyolefins and related blends and composites on microstructural and molecular characteristics. Macromolecular Symposia, 143, 185-205 (1999). DOI: $10.1002 /$ masy. 19991430115
[19] Ferrer-Balas D., Maspoch M. L., Mai Y-W.: Fracture behaviour of polypropylene films at different temperatures: Fractography and deformation mechanisms studied by SEM. Polymer, 43, 3083-3091 (2002).

DOI: 10.1016/S0032-3861(02)00102-7

[20] Ferrer-Balas D., Maspoch M. L., Martinez A. B., Ching E., Li R. K. Y., Mai Y-W.: Fracture behaviour of polypropylene films at different temperatures: Assessment of the EWF parameters. Polymer, 42, 2665-2674 (2001). DOI: $10.1016 / \mathrm{S} 0032-3861(00) 00603-0$

[21] Hashemi S., Arkhireyeva A.: Influence of temperature on work of fracture parameters in semi-crystalline polyester films. Journal of Macromolecular Science Part B: Physics, 41, 863-880 (2002). DOI: $10.1081 / \mathrm{MB}-120013070$

[22] Hashemi S.: Temperature dependence of work of fracture parameters in polybutylene terephthalate (PBT). Polymer Engineering and Science, 40, 1435-1446 (2000).

DOI: $10.1002 /$ pen.11273

[23] Pegoretti A., Castellani L., Franchini L., Mariani P., Penati A.: On the essential work of fracture of linear low-density-polyethylene. I. Precision of the testing method. Engineering Fracture Mechanics, 76, 27882798 (2009). DOI: $10.1016 /$ j.engfracmech.2009.05.013

[24] Gupta P., Wilkes G. L., Sukhadia A. M., Krishnaswamy R. K., Lamborn M. J., Wharry S. M., Tso C. C., DesLauriers P. J., Mansfield T., Beyer F. L.: Does the length of the short chain branch affect the mechanical properties of linear low density polyethylenes? An investigation based on films of copolymers of ethylene/1-butene, ethylene/1-hexene and ethylene/1-octene synthesized by a single site metallocene catalyst. Polymer, 46, 8819-8837 (2005).

DOI: $10.1016 /$ j.polymer.2005.05.137

[25] Ferrer-Balas D., Maspoch M. L., Martinez A. B., Santana O. O.: Influence of annealing on the microstructural, tensile and fracture properties of polypropylene films. Polymer, 42, 1697-1705 (2001). DOI: $10.1016 / \mathrm{S} 0032-3861(00) 00487-0$

[26] Karger-Kocsis J.: Toward understanding the morphology-related crack initiation and propagation behavior in polypropylene systems as assessed by the essential work of fracture approach. Journal of Macromolecular Science Part B: Physics, 38, 635-646 (1999). DOI: $10.1080 / 00222349908248127$

[27] Sheng B-R., Li B., Xie B-H., Yang W., Feng J-M., Yang M-B.: Influences of molecular weight and crystalline structure on fracture behavior of controlled-rheology-polypropylene prepared by reactive extrusion. Polymer Degradation and Stability, 93, 225-232 (2008). DOI: $10.1016 /$ j.polymdegradstab.2007.09.011 
[28] Mouzakis D. E., Gahleitner M., Karger-Kocsis J.: Toughness assessment of elastomeric polypropylene (ELPP) by the essential work of the fracture method. Journal of Applied Polymer Science, 70, 873-881 (1998).

DOI: 10.1002/(SICI)1097-4628(19981031)70:5<873:: AID-APP6>3.0.CO;2-Q

[29] Wallner G. M., Major Z., Maier G. A., Lang R. W.: Fracture analysis of annealed PVDF films. Polymer Testing, 27, 392-402 (2008).

DOI: $10.1016 /$ j.polymertesting.2008.01.006

[30] Barry D. B., Delatycki O.: The effect of molecular structure and polymer morphology on the fracture resistance of high-density polyethylene. Polymer, 33, 1261-1265 (1992).

DOI: $10.1016 / 0032-3861(92) 90772-O$

[31] Channell A. D., Clutton E. Q.: The effects of short chain branching and molecular weight on the impact fracture toughness of polyethylene. Polymer, 33, 41084112 (1992).

DOI: $10.1016 / 0032-3861(92) 90613-2$

[32] Wunderlich B.: Thermal analysis of polymeric materials. Springer, Berlin (2005).

[33] Bárány T., Ronkay F., Karger-Kocsis J., Czigány T.: In-plane and out-of-plane fracture toughness of physically aged polyesters as assessed by the essential work of fracture (EWF) method. International Journal of Fracture, 135, 251-265 (2005).

DOI: $10.1007 / \mathrm{s} 10704-005-3947-2$

[34] Men Y., Rieger J., Strobl G.: Role of the entangled amorphous network in tensile deformation of semicrystalline polymers. Physical Review Letters, 91, 095502/1-095502/4 (2003).

DOI: 10.1103/PhysRevLett.91.095502

[35] Michler G. H.: Kunststoff-Mikromechanik. Hanser, München (1992).

[36] Hu H., Dorset D. L.: Crystal structure of poly(i६caprolactone). Macromolecules, 23, 4604-4607 (1990). DOI: $10.1021 / \mathrm{ma} 00223 \mathrm{a} 017$

[37] Zhang Y., Leblanc-Boily V., Zhao Y., Prud'homme R.E.: Wide angle $\mathrm{X}$-ray diffraction investigation of crystal orientation in miscible blend of poly( $\varepsilon$-caprolactone)/poly(vinyl chloride) crystallized under strain. Polymer, 46, 8141-8150 (2005).

DOI: $10.1016 /$ j.polymer.2005.06.114

[38] Crescenzi V., Manzini G., Calzolari G., Borri C.: Thermodynamics of fusion of poly- $\beta$-propiolactone and poly- $\varepsilon$-caprolactone. comparative analysis of the melting of aliphatic polylactone and polyester chains. European Polymer Journal, 8, 449-463 (1972). DOI: $10.1016 / 0014-3057(72) 90109-7$
[39] Marchal Y., Walhin J-F., Delannay F.: Statistical procedure for improving the precision of the measurement of the essential work of fracture of thin sheets. International Journal of Fracture, 87, 189-199 (1997). DOI: 10.1023/A:1007482121146

[40] Clutton E.: Essential work of fracture. European Structural Integrity Society, 28, 177-195 (2001).

DOI: 10.1016/S1566-1369(01)80033-9

[41] Tuba F., Oláh L., Nagy P.: Essential work of fracture study of polymers: A novel criterion for the validation of tested ligament range. Journal of Materials Science, 46, 7901-7904 (2011).

DOI: $10.1007 / \mathrm{s} 10853-011-5778-\mathrm{Z}$

[42] Tuba F., Oláh L., Nagy P.: On the valid ligament range of specimens for the essential work of fracture method: The inconsequence of stress criteria. Engineering Fracture Mechanics, 99, 349-355 (2013).

DOI: $10.1016 /$ j.engfracmech.2012.12.011

[43] Tuba F., Oláh L., Nagy P.: The role of ultimate elongation in the determination of valid ligament range of essential work of fracture tests. Journal of Materials Science, 47, 2228-2233 (2012). DOI: $10.1007 / \mathrm{s} 10853-011-6033-3$

[44] Macosko C. W.: Rheology: Principles, measurements and applications. Wiley-VCH, Weinheim (1994).

[45] Izuka A., Winter H. H., Hashimoto T.: Molecular weight dependence of viscoelasticity of polycaprolactone critical gels. Macromolecules, 25, 2422-2428 (1992). DOI: 10.1021/ma00035a020

[46] Skoglund P., Fransson Å.: Continuous cooling and isothermal crystallization of polycaprolactone. Journal of Applied Polymer Science, 61, 2455-2465 (1996).

DOI: 10.1002/(SICI)1097-4628(19960926)61:13<2455 $\because$ AID-APP25>3.0.CO;2-1

[47] Pitt C. G., Chasalow F. I., Hibionada Y. M., Klimas D. M., Schindler A.: Aliphatic polyesters. I. The degradation of poly( $\varepsilon$-caprolactone) in vivo. Journal of Applied Polymer Science, 26, 3779-3787 (1981). DOI: 10.1002/app.1981.070261124

[48] Bodor G.: Structural investigation of polymers. Ellis Horwood, New York (1991).

[49] Chen H-L., Li L-J., Ou-Yang W-C., Hwang J. C., Wong W-Y.: Spherulitic crystallization behavior of poly( $\varepsilon-$ caprolactone) with a wide range of molecular weight. Macromolecules, 30, 1718-1722 (1997).

DOI: $10.1021 / \mathrm{ma} 960673 \mathrm{v}$

[50] Tuba F.: Fracture tougness - microstructure relationships in biodegradable medical polymers. PhD Thesis in 'Department of Polymer Engineering, Budapest University of Technology and Economics', Budapest (2012).

[51] Dinnebier R. E., Billinge S. J. L.: Powder diffraction Theory and practice. The Royal Society of Chemistry, Cambridge (2008). 